$\underline{\text { Research Articles }}$

\title{
Defining an action-research's content to improve a policy supporting indigents' health in Mali: a concept mapping
}

\author{
Mathieu Seppey ${ }^{1}$ (D), Laurence Touré ${ }^{2}$, Valéry Ridde ${ }^{3}$ (D) \\ 1 Université de Montréal, École de santé publique (ESPUM), Département de médecine sociale et préventive, Montréal (Québec), Canada; Centre de \\ Recherche en Santé Publique (CReSP), Montréal, Québec, Canada, ${ }^{2}$ MISELI, Bamako, Mali, ${ }^{3}$ IRD (Research Institute for Sustainable Development), \\ CEPED, Université de Paris, ERL INSERM SAGESUD Paris, France
}

Keywords: action-research, healthcare access, mali, health policy, concept mapping

https://doi.org/10.29392/001c.21956

\section{Journal of Global Health Reports}

Vol. 5, 2021

\begin{abstract}
Background
Concept mapping $(\mathrm{CM})$ is a method used to create consensus around a concept within a group of actors, which enables an empowering process for the participants through dialogues and shared information. We performed a CM, aiming to improve the operationalisation of a health policy, the RAMED, to promote healthcare access to the indigent population in Mali.
\end{abstract}

\section{Methods}

The CM followed five steps leading to the conceptual map development: 1) brainstorming, 2) statements' scoring, 3) clustering, 4) statistical (hierarchical clustering and multi-dimensional scaling) and qualitative analysis, and 5) validating the map. Twenty-seven participants took place in the CM, representing eighteen organisations linked to the implementation of the policy.

\section{Results}

We identified seven clusters of activities towards finding the concrete and collective solutions to improve healthcare access: "funding strengthening," "integral management and care of indigents," "expertise creation," "promotion and communication,” "indigents' identification processes," "monitoring and evaluation," and "integration and coordination of actors." According to scalability and priority scores, "identification processes" was the most scalable and important cluster (3.03 $[ \pm 0.51]$ and $3.26[ \pm 0.47] / 4$ respectively), while "funding strengthening" was the least scalable and important $(2.59[ \pm 0.47]$ and 2.76 $[ \pm 0.42] / 4$ respectively).

\section{Conclusions}

Although this method is primarily exploratory and a great starting point for further collaborative research, it managed to highlight the two fundamental issues in action-research: the difficulty related to the knowledge transfer to vulnerable populations and their lack of participation in the research process. It is particularly an issue in West Africa, due to lack of empirical studies and high poverty levels. Results of this study demonstrate that CM offers an important starting point for improvements, which should focus on knowledge transfer and inclusion of vulnerable populations' points of view.

In most West African countries, health service users, including the poorest (indigents), are required to pay fees when they consult health care providers. ${ }^{1}$ Despite numerous studies showing that out-of-pocket payment is unfavourable, its use persists, increasing inequalities in the use of care and resulting in wider-scale exclusion of indigents from the health system. ${ }^{2}$ The term "indigent" (or worst-off) is largely used in the West African contexts and is composed of many criteria depending on the context where it is used. ${ }^{3}$ We use this term to be coherent with its use by the Régime d'Assistance Médicale (RAMED).
Following the examples of Algeria, ${ }^{4}$ Tunisia, ${ }^{5}$ or Morocco, ${ }^{6}$ Mali is one of the rare West African countries to have a public policy designed to provide free access to health services for indigents. ${ }^{7}$ For operational purposes, Malian officials decided that indigents would represent the poorest $5 \%$ of the general population in Mali. The package of care offered to that population is equivalent to the one offered to the beneficiaries of compulsory health insurance (AMO), except for the specialty drug coverage. ${ }^{8}$

In 2009, the State introduced a non-contributory scheme, the RAMED which is dedicated to care for the in- 
digent; that is, to "any person without resources and recognized as such by the territorial community to which he belongs". ${ }^{9}$ It is publicly funded from the State and local authorities $^{7}$ and is managed by the Agence Nationale Assistance Médicale (ANAM), a national public administrative institution with legal personality and financial autonomy. ${ }^{10} \mathrm{It}$ is responsible for registering beneficiaries and is under the Ministry of Solidarity and Humanitarian Action (MSAH).

Nearly ten years after its launch, RAMED was reported suffering from several operational implementation problems, including difficulty selecting and defining indigence, especially in conditions where the poverty rate is very high. Unlike other countries that have enacted such policies without providing the means, ${ }^{2}$ Mali has public funding that could enable it to provide access to care for the indigent. Yet, the proportion of registered indigent people remains low: in 2019, 732348 were selected and registered compared to the target of 950000 .

In the context of a partnership between an interdisciplinary research team and ANAM actors, we collectively decided to engage in action research to find operational solutions to improve indigents' care and make RAMED more functional. ${ }^{7}$ An action-research was justifiable by the need for ANAM agents to find concrete and collective solutions (e.g., problems in defining and operationalizing a policy of free care for the indigent). ${ }^{11-13}$ This responds to the lack of evidence about interventions in favour of the poorest in Africa. ${ }^{13,14}$ A workshop was organised in February 2019. It mobilized 27 experts from national and regional organisations, who had experiential knowledge to identify actions to be tested within this action-research. ${ }^{11}$

The workshop started with a presentation of the context of the RAMED policy and its results by ANAM. The researchers shared the results of their research on the emergence, processes, and effectiveness of the targeting of this same policy. This process revealed the main challenges (Online Supplementary Document, Box 1). Next, there was a short theoretical presentation of the foundations (particularly West African ${ }^{15}$ ) of action research, its definition ("Action research is only possible WITH, FOR and BY people and communities, involved both in questioning and in the production of meaning, to inform research AND the action of which it is the core," adapted from Reason and Bradbury 200111), its principles, its processes, and its stages. A film taken from one of our action-research projects in Burkina Faso illustrated these different stages, from the preliminaries to its conclusion (link to the film: https://www.youtube.com/watch?v=MnUTi3FwIkc). Finally, we explained the logistical and financial framework of action research (Online Supplementary Document, Box 2). The actions needed to be feasible and take these guidelines into account.

The aim of this study was to present the whole of this approach and the content that the participants proposed to improve the RAMED system's operationality to promote access to health care for the indigent in Mali. Beyond their national relevance, the results of this study may provide support to other decision-makers in other West African countries who wish to engage in such public policies a priori favourable to equity and universal health coverage.

\section{METHODS}

This study is based on the specific type of a group consensual approach, the concept mapping (CM). This method was previously validated in Africa, ${ }^{3}$ where it was shown not only to be effective, but also a tool for empowering the different stakeholders. ${ }^{16,17}$ It can initiate dialogue and help share information by creating a map based on the stakeholders' ideas; in turn, helps them acquire a more holistic view of the topic and see how it can be better integrated with their own interventions and practices. ${ }^{18}$

The method of CM answers many challenges linked to qualitative methods. While some participants can hijack the discussion, CM maintains a more equitable space for sharing ideas, whether a participant has a higher status or not. ${ }^{19}$ CM structures the discussion into round table turns; it allows every participant to speak up without being criticized or seeing the idea argued. The importance and legitimacy of every idea is underlined before and during the CM. ${ }^{20}$

\section{DATA COLLECTION}

We conducted the CM process on the 7th of February 2019. Before the CM, contextual information and preliminary research results about the RAMED's challenges were shared through policy briefs and discussed with the participants. ${ }^{21-25}$ We defined the CM's objective as to collectively identify a list of actions to test, in the context of the action research, to facilitate the operationalisation of a reimbursement system by the RAMED.

The research team recruited twenty-seven participants who were based in Bamako and represented different organisations (Online Supplementary Document, Table S1). This purposeful sample was based on the various organisations that could be related to the implementation of the intervention and the participants' expertise regarding indigence in their intervention.s This purposive sampling method helped get more detailed information during data collection. ${ }^{19,26}$

Literature presents many different steps to conduct a CM. ${ }^{16,27}$ However, we used the five steps of Trochim (1989), as they are the most clearly defined. The first step is a qualitative data collection process, which is used to collect the statements on the topic. These statements are then taken into the second step, where everyone scores every statement regarding its scalability and priority. The third step is a mixed data collection with the creation of groupings/ clusters, which are qualitatively named and calculated as frequency of aggregation. This grouping of statements allows for a quantitative analysis, using the hierarchical cluster analysis (HCA), followed by a multi-dimensional scaling (MDS), ${ }^{27}$ and a content analysis of the statements and their clusters, which is the fourth step. A restitution of the data with the research's technical committee was organised as the fifth step, to validate the conceptual map.

\section{STEP 1- BRAINSTORMING}

All participants $(\mathrm{N}=27)$ brainstormed and responded to the statement: "to promote access to health care for the indigent in Mali by improving the RAMED system's operational- 
ity, I will propose to test in an action research...”. Being part of the steering committee and therefore an integral part of the action-research, one of the co-authors of this article was one of the 27 participants and proposed responses to the statements. Each participant could express as many proposals as he or she wished. If necessary, the facilitator made sure that the proposal responded to the specific statement, was clear, understood by all, formulated only one idea, and had not been proposed previously. As they were produced, the two research assistants wrote the statements on a flipchart to allow participants to see the proposals, draw inspiration from them, and avoid repeating them. A third person entered them into a Word file.

\section{STEP 2- STATEMENTS' SCORING}

A research assistant distributed the list of statements to the participants $(\mathrm{N}=25)$. The assistant asked the participants to score every statement regarding their scalability (ability to act the statement at a national level) and their priority (importance to test the statement). The scores were scaled from 1 to 5 , where 5 was being extremely scalable/important and 1 being not very scalable/important. There was no interaction between participants at this stage.

\section{STEP 3- CLUSTERS}

Research assistants put all the statements on individual vignettes to be regrouped by the participants $(\mathrm{N}=25)$. All statements had to be put into one pile (a minimum of two piles is required from the participants) of at least two statements. All clusters had to make sense to the participant according to his/her emic perspective, who will give a name and list the statements' numbers for each cluster. We calculated frequencies through the number of associations between statements after all clusters from all participants were aggregated. No interaction was needed for this step.

\section{STEP 4- HIERARCHICAL CLUSTER ANALYSIS (HCA) \& MULTI-DIMENSIONAL SCALING (MDS)}

Through the frequencies from the clusters, we conducted an HCA followed by an MDS. ${ }^{27}$ To prepare those analyses, we created a binary matrix for all the participants' clusters, where $1=$ an association between two statements and 0 $=$ the absence of association. ${ }^{18}$ We aggregated all matrices into a final proximity matrix, which added all the associations between statements. HCA consisted of remodelling the participants' clusters according to the final matrix. ${ }^{28}$ This analysis was bottom-up (unweighted pair group method with arithmetic mean: UPGMA); we associated the closest two statements first, then we calculated the second closest association (between statements, a statement and a group or groups), and so on, until there were no standalone statements (ex.: dendrogram). ${ }^{29}$ We used UPGMA since it enabled us to account for proximities between clusters, using proximity averages between each statement (and not only between clusters). The bottom-up analysis was more adaptable than a top-down approach, which would have identified variables (that would not be clearly identifiable in the statements), enabling the division of statements in different distinctive groups (this approach is more present in biological taxonomy, for example). ${ }^{30}$ Following the HCA and still from the final proximity matrix, a MDS determined the Euclidian distance between the statements on a 2D map, using the different frequencies calculated. ${ }^{18,27} \mathrm{We}$ made a descriptive analysis of the scores (scalability and priority) by calculating the average of all scores for each statement. We conducted all analyses on the software R ( R core team, Vienna, Austria).

In addition to those quantitative analyses, we performed a qualitative content analysis of the participants' different statements and clusters' names. This qualitative conventional content analysis ${ }^{31}$ is justified by the exploratory aspect of the study design, emphasizing the stakeholders' experiences regarding identification of indigents. This analysis followed the steps of 1) preparation of the raw data, that are computerised on the software QDA Miner (Provalis Research, Montréal, Canada), 2) familiarisation with the data (ex.: re-reading of the data), 3) inductive identification of themes (ex.: use of words and meanings from the participants' data), 4) codification (ex.: segmentation of the statements in units of analysis); and 5) organisation of codes/ themes (Online Supplementary Document, Table S2). ${ }^{19}$ Following this analysis, we chose the number and names of clusters for the cartography. To choose the number of clusters, we linked the qualitative assessment of the statements to the HDS. We analysed different alternatives of clusters and chose the most sensible alternative (qualitatively).

\section{STEP 5- RESTITUTION AND VALIDATION OF THE MAP}

The final step was a restitution session $(\mathrm{N}=8)$, organized in two workshops, with the research's technical committee that helped validate thesuppls map and go further in comprehending the map and the actions to pursue in the action research. The facilitator asked participants to provide further insights, reiterate their points of view, or provide explanations or clarifications about some surprising results. ${ }^{18,32}$

\section{ETHICS APPROVAL}

This study was part of a larger research program called "Results-based financing for equitable access to maternal and child health care in Mali and Burkina Faso" which received ethical authorisation from the Institut National de Recherche en Santé Publique in Bamako, Mali (N17/2016/CE-INRSP). This ethical authorisation insured confidentiality of shared information, consent, and anonymity of participants.

\section{RESULTS}

\section{GENERAL CONCEPTUAL MAPPING}

Following the first stage of the CM, the authors put the participants' statements (Online Supplementary Document, Table S3) into binary matrices. This resulted in a final aggregated matrix of frequencies and the production of a dendrogram (Figure 1), where clusters were made between the closest statements (or closest clusters). For the lecture of the dendrogram, we put each statement (at the bottom) in relation with another (or with a cluster). The closer state- 
ments are, the closer to the bottom their link " $\cap$ " is for example, the statements 84 and 98 (last statements of the first cluster) are the closest since they were associated 24 times by the participants.

Following the different proximities between the statements and a qualitative assessment of the statements and possible clusters, we created seven abstracted clusters based on a heuristic approach: 1) Fund strengthening [orange] (21 statements), 2) Integral management and care of indigents [green] (22 statements), 3) Expertise creation [pink] (9 statements), 4) Promotion/Communication linked to the RAMED [brown] (20 statements), 5) Indigents identification processes [red] (35 statements), 6) Monitoring and evaluation [violet] (13 statements), and 7) Integration and coordination of actors [blue] (6 statements). VR and LT validated the process by independently analysing the statements and making the same seven clusters (with some minor variations in their naming).

Still with the final matrix of frequencies/proximities, we performed an MDS analysis (Euclidian distance) to put the different statements on a scatter plot (Figure 2). We then apposed the clusters from the HCA on the scatter plot (Figure 3) (Figure 4). The three main axes show proximity between different elements of the actions to be undertaken by the RAMED to take into account indigents in the health system: 1) Green \& Orange axis (Funding and Management), 2) Pink \& Brown axis (Expertise and Communication), and 3) Red, Violet, \& Blue axis (Identification, Monitoring and evaluation, and Coordination).

\section{CLUSTERS}

Since we inductively analysed each statement, different types of actors, actions, and processes have emerged and can be related to the other clusters.

\section{FUNDING STRENGTHENING (ORANGE)}

Statements bring attention to the localities as important actors in the sustainment of funding. Different taxes could be put in place regarding private actors (ex.: telecommunication, mining) and other sectors (ex.: transports, municipalities, health, consumption). The State's role was not clearly defined, apart from its implicit place in new taxations, in comparison to the role of localities and actors from other sectors. The main actions thought to be required to strengthen the funding strategies are based on the creation of new funding strategies (ex.: new taxes) and their decentralisation (ex.: involving investments from local actors).

\section{INTEGRAL MANAGEMENT AND CARE OF INDIGENTS (GREEN)}

The role of health organisations was central, with the implication of pharmacies and the State to a lesser extent. The statements did not identify the role of indigents in their own care. They identified new improvements to indigents' management and care such as mobile care, free-of-charge care (for example, subsidised pharmacies), better reception of indigents, or the diminution/absence of rupture of medicines. The statements identified the need for new standards

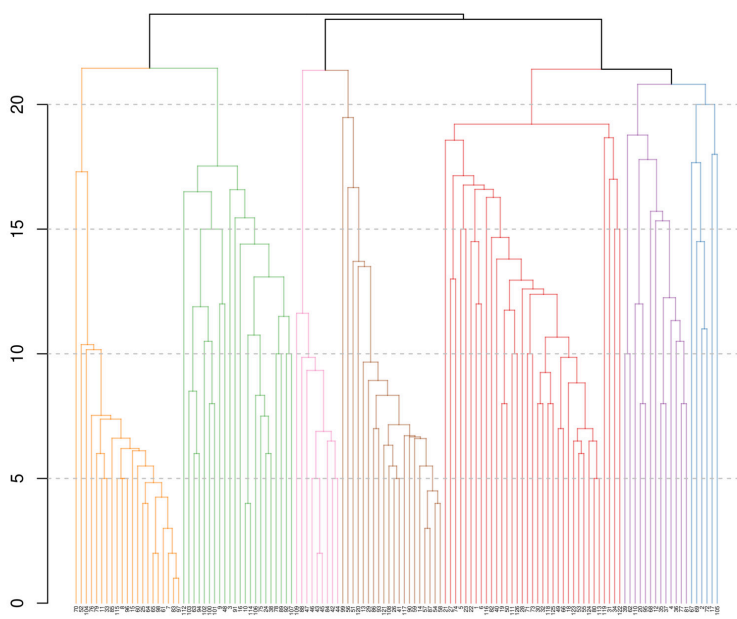

Figure 1. Statements' dendrogram.

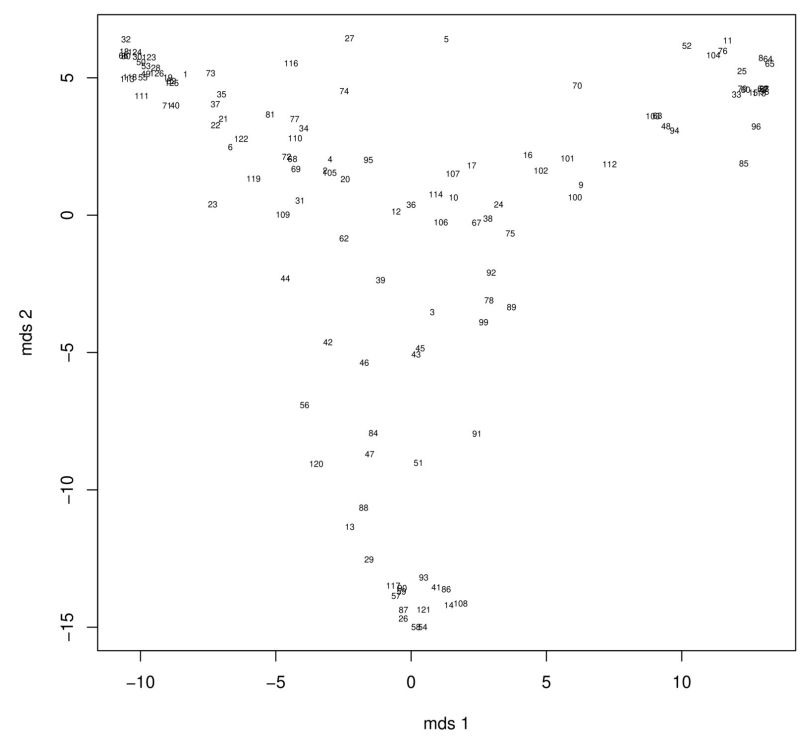

Figure 2. Statements' scatter plot (MDS analysis).

that are nation-wide, have a minimal package of services, and promote accessible services. To reach those standards, it would be necessary to reorganise the health system by increasing resources (ex.: financial or human), points of services, and the quality of services. The statements did not detail services; they emphasized integration of services and their continuity for the indigent.

\section{CREATION EXPERTISE (PINK)}

To have effective actions, all actors seem to be concerned about a lack of expertise and a need to be trained, whether 
at a more implementation level or a decision one. That training responsibility rested mainly on the research team. While the participants identified the need for more training, they reported few specific aspects in the statements (ex.: training on how to fill in medical forms, how to identify indigents, or how to vulgarise indigence criteria).

\section{PROMOTION/COMMUNICATION LINKED TO THE RAMED (BROWN)}

The promotion and communication linked to the RAMED mainly targeted localities and to a lesser extent the State, health organisations, the private sector, and the indigents. The project's team was central to the creation of the promotion and communication strategies. The aims of these strategies should be to motivate the inclusion of indigents in the health systems (ex.: giving prices), to decentralise and to put to scale the information (ex.: local sessions of information and national day for indigents), and to clarify the status of indigence (ex.: giving a voice to the indigent population, translation into local language). Both the identification and the management/care of indigents were the central themes of a potential promotion and communication strategy.

\section{IDENTIFICATION PROCESSES (RED)}

The project's team had an important role in the identification process by elaborating the activities and tools of identification, training the actors, harmonising the criteria, etc. The administrative authorities and health organisations representing the different territorial units (regions, cercles, and communes) also played a role in the implementation of the identification process. It is worth noting that, like for the funding strengthening, the State had few responsibilities in this cluster. This cluster is more implementing activities than the other clusters, with different stages to go through for the identification of indigents (ex.: testing tools, select indigents, engage with localities, and computerise information). Much of the actions had to be created and decentralised before being implemented. The importance of coordination and effective registration were central in the identification process, whereas the participants less identified implication of actors, the monitoring and evaluation or the management/care of indigents.

\section{MONITORING AND EVALUATION (VIOLET)}

The monitoring and evaluation were the pilot project's responsibility through the evaluation of the implementation context. Other actors such as the health organisations then had the responsibility to put into effect the evaluations and monitoring's recommendations. The monitoring and evaluation of the project did not involve higher levels in the health system reinforcement of the control system at central level in Bamako. New actors could take the responsibility of monitoring and evaluation (ex.: an autonomous observatory of indigence). The monitoring and evaluation process was linked to the issue of fraud, indigent's satisfaction, and the project's implementation.

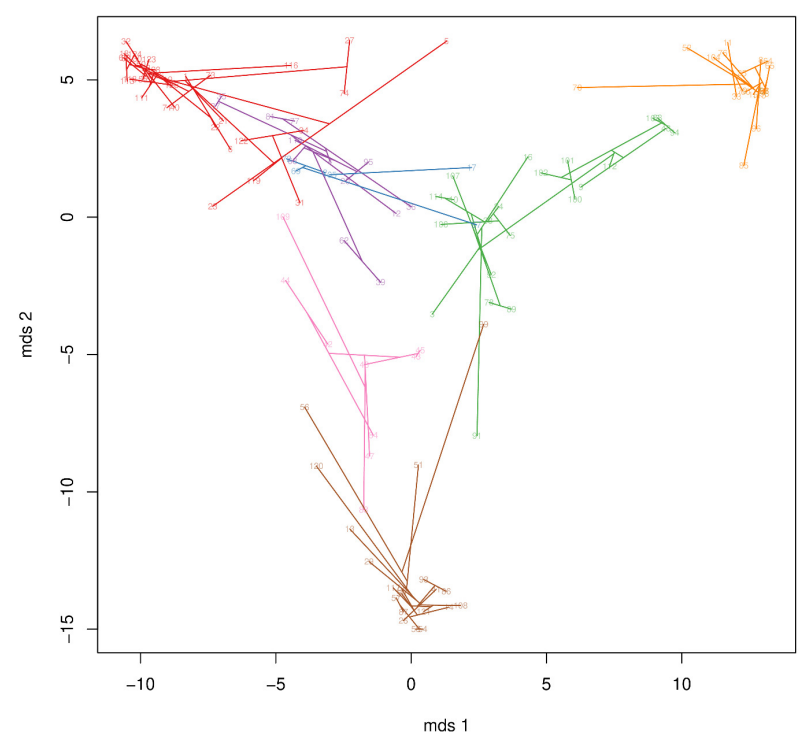

Figure 3. Clustered statements (HC analysis).

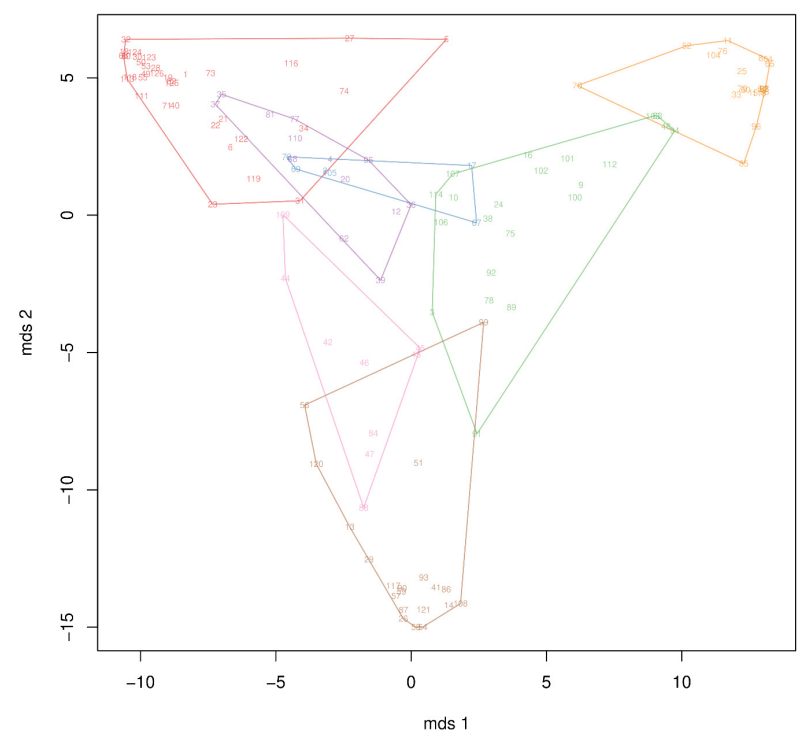

Figure 4. Clustered statements with polygons (HC analysis).

\section{INTEGRATION AND COORDINATION OF ACTORS (BLUE)}

More coordination was needed around the RAMED, creating a need to create new instances (ex.: local committees), new work organisations, or practices (ex.: integration of social services, community mechanisms to support indigents' social reinsertion). By recognizing indigence as a multisectoral issue, the coordination of actors went beyond the health system to include intervention of the educational system, communities, or social services. These services' in- 
tegration and coordination of actors brought a need to create new mechanisms and ways to approach the issue of indigence, through more proximity between services and the concerned population.

\section{CLUSTERS' SCORES}

We scored each statement on a scale of 1-5 regarding the possibility to adopt the action at a national level (scalability) and the importance of that statement (priority) (Figure 5) (Figure 6). Based on each cluster's the average and median score, the least scalable and least important cluster was about fund strengthening (orange). The identification process cluster (red) was the most scalable and important (Table 1). The ten most "scalable" and ten most "important" statements were mainly from the identification process cluster (Table 2). A coefficient of correlation of 0.84 $(\mathrm{P}<0.001)$ can be found between the statements' priority and scalability (Figure 7).

\section{DISCUSSION}

While CM has rarely been used in Africa, previous experiences in Burkina Faso $3,33,34$ and other African countries ${ }^{35,36}$ show that it is adaptable in different regions. This method was an interesting starting point for a long-term process that is action research, aiming at both participation and rigour. ${ }^{11,37}$ This technique created a collective and trusting dynamic with knowledge transfer at the heart of participatory action research. ${ }^{38}$ As it is shown in Burkina Faso to combat dengue fever, it is necessary to consider the most recent and context-relevant evidence, and to have knowledge of the context of the actions envisaged and the needs of the people concerned. 39

This experience of setting up a CM in Mali provided an opportunity to share some advice for people who would like to use it in a similar context. A first challenge was to be able to bring together the most relevant stakeholders for collective discussions. In this type of context, where multiple workshops are organised and where the relevant people are not always present, we had to take the time to identify the most relevant stakeholders beforehand. ${ }^{40}$ The collaboration with the steering committee and the fact that this CM was an integrated activity within the action research made the selection of people more effective. Following, it is necessary to have a plurality of voices by having a variety of people representing the diversity of the organisations involved. During the facilitation of the brainstorming stage, it is important to ensure there are no comments on the individual responses proposed. The facilitator must guide conversation, so the debates do not flare up. In a social context that is often hierarchical and patriarchal, it was important to lead the session distributing the discussion as openly as possible, leaving room for women, young people, and other marginalised populations to express their opinions. It is useful to plan sufficient time to allow people to carry out the rating and sorting activities. Carrying out a CM in a context where there are logistical challenges (electricity, room layout, printer, documents, etc.) requires preparation and the presence of several people in back-up. In the end, the participants appreciated the dynamic, participative, and

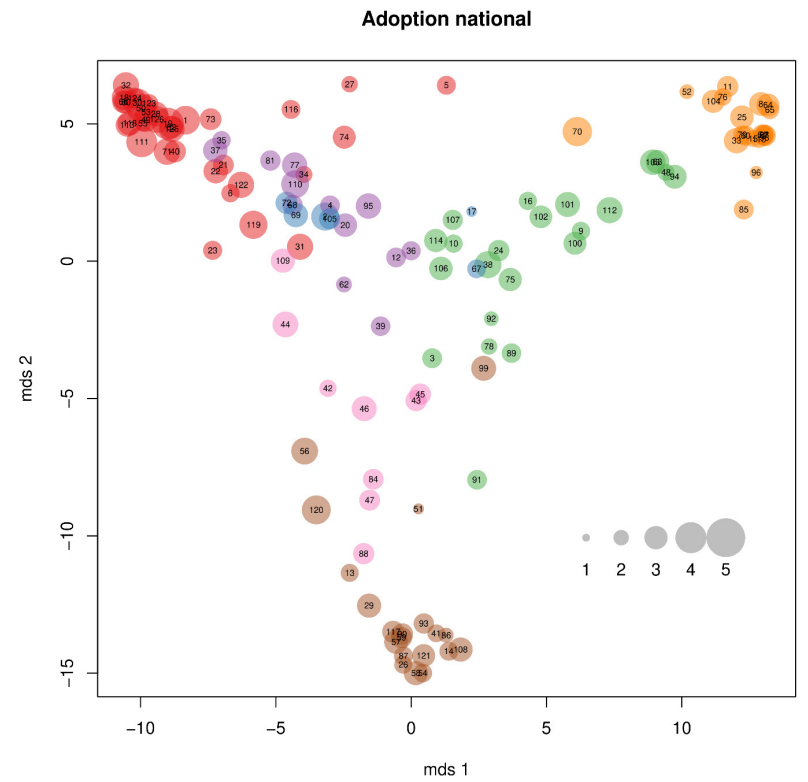

Figure 5. Statements' scalability scores.

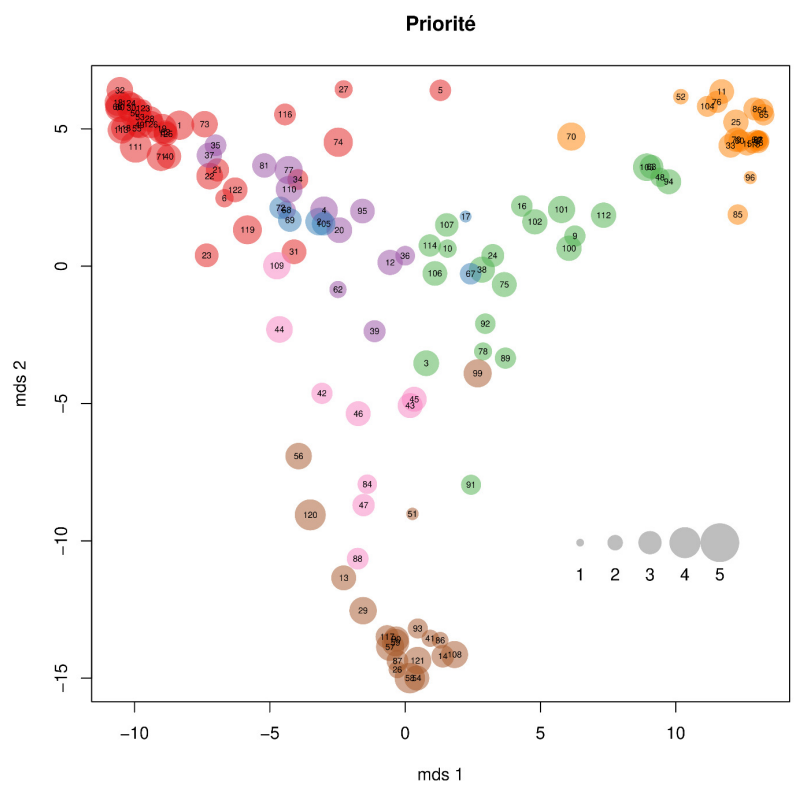

Figure 6. Statements' priority scores.

systematic nature of the method and their participation in the subsequent analysis. ${ }^{39}$

One of the major challenges in the West African region is the significant lack of scientific knowledge about what needs to be done to ensure that indigent people have access to care. As much as the problem has been described by scientists ${ }^{41}$ and highlighted in public policies for a long time, ${ }^{42}$ there are few ideas on how to proceed. This limitation was illustrated in the $2000 \mathrm{~s}^{43}$ and reiterated in a recent systematic review that confirms the scarcity of effective solutions. This review aimed to identify health trajectory interventions to support the indigent in their use of care in 
Table 1. Clusters' aggregated scores for scalability and priority

\begin{tabular}{|l|c|c|}
\hline & Scalability & Priority \\
\hline Clusters & Average score (SD) & Average score (SD) \\
\hline Funding strengthening [Orange] & $2.59( \pm 0.47)^{*}$ & $2.76( \pm 0.42)^{*}$ \\
\hline Integral management and care of indigents [Green] & $2.76( \pm 0.42)$ & $2.99( \pm 0.36)$ \\
\hline Expertise creation [Pink] & $2.84( \pm 0.34)$ & $3.07( \pm 0.34)$ \\
\hline Promotion/Communication linked to the project [Brown] & $2.72( \pm 0.53)$ & $3.10( \pm 0.63)$ \\
\hline Identification processes [Red] & $3.03( \pm 0.51)^{* *}$ & $3.26( \pm 0.47)^{* *}$ \\
\hline Monitoring and evaluation of the project [Violet] & $2.77( \pm 0.43)$ & $3.052308( \pm 0.43)$ \\
\hline Integration and coordination of actors [Blue] & $2.68( \pm 0.69)$ & $2.80( \pm 0.62)$ \\
\hline
\end{tabular}

*: Least scalable and important cluster

**: Most scalable and important cluster

\begin{tabular}{|c|c|c|c|c|c|}
\hline \# & Statements & Scalability & Priority & Statements & \# \\
\hline 19 & Definition of indigence criteria [Red] & 4.11 & 4.08 & Review the social survey form [Red] & 111 \\
\hline 111 & Review the social survey form [Red] & 3.96 & 4 & $\begin{array}{l}\text { Translation of concepts related to indigence into } \\
\text { local languages [Brown] }\end{array}$ & 120 \\
\hline 70 & $\begin{array}{l}\text { Set up a system for the diligent } \\
\text { reimbursement of health services [Orange] }\end{array}$ & 3.78 & 3.96 & $\begin{array}{l}\text { Harmonize the criteria for the selection of } \\
\text { indigents [Red] }\end{array}$ & 50 \\
\hline 50 & $\begin{array}{l}\text { Harmonize the criteria for the selection of } \\
\text { indigents [Red] }\end{array}$ & 3.74 & 3.93 & $\begin{array}{l}\text { Widely inform the communities about the } \\
\text { selection process of the indigent people [Brown] }\end{array}$ & 58 \\
\hline 120 & $\begin{array}{l}\text { Translation of concepts related to indigence } \\
\text { into local languages [Brown] }\end{array}$ & 3.73 & 3.85 & $\begin{array}{l}\text { Establishment of village committees for the } \\
\text { identification of indigent people [Red] }\end{array}$ & 80 \\
\hline 1 & $\begin{array}{l}\text { Accelerate matriculation processes and } \\
\text { distribution of indigent cards [Red] }\end{array}$ & 3.7 & 3.85 & Definition of indigence criteria [Red] & 19 \\
\hline 119 & $\begin{array}{l}\text { Test the computerization of the entire file } \\
\text { up to the ANAM [Red] }\end{array}$ & 3.63 & 3.81 & $\begin{array}{l}\text { Develop a manual for targeting the urban and rural } \\
\text { indigents [Red] }\end{array}$ & 30 \\
\hline 30 & $\begin{array}{l}\text { Develop a manual for targeting the urban } \\
\text { and rural indigents [Red] }\end{array}$ & 3.63 & 3.78 & $\begin{array}{l}\text { Putting interviewers in the right conditions for } \\
\text { carrying out social surveys [Red] }\end{array}$ & 74 \\
\hline 2 & $\begin{array}{l}\text { Improve the coordination of the actors } \\
\text { involved in RAMED [Blue] }\end{array}$ & 3.6 & 3.77 & $\begin{array}{l}\text { Accelerate matriculation processes and distribution } \\
\text { of indigent cards [Red] }\end{array}$ & 1 \\
\hline 110 & $\begin{array}{l}\text { Strengthen system control in Bamako } \\
\text { [Violet] }\end{array}$ & 3.58 & 3.73 & $\begin{array}{l}\text { Test the computerization of the entire file up to the } \\
\text { ANAM [Red] }\end{array}$ & 119 \\
\hline
\end{tabular}

\section{Table 2. Ten most scalable and priority statements [clusters]}

Orange: Funding strengthening. Green: Integral management and care of indigents. Pink: Expertise creation. Brown: Promotion/Communication linked to the project. Red: Identification processes. Violet: Monitoring and evaluation of the project. Blue: Integration and coordination of actors.

low- and middle-income countries. ${ }^{14}$ Unfortunately, no interventions specifically focused on supporting the indigent have been found in the scientific literature, particularly in Africa. The slogan "leaving no one behind" pushed by international organizations, particularly the World Health Organization for universal health coverage, ${ }^{44}$ is still far from being a reality in West African countries. Thus, this research in Mali enabled the actors concerned to propose courses of action whose effectiveness will need to be tested, and whose implementation and adaptation to the context will need to be understood.

Regarding the level of knowledge of the context and needs, one of the important limitations of this exercise was the direct involvement of the poor. Indeed, the ethical issues of mobilizing the poorest people in a context of almost generalized poverty are complex to address. ${ }^{45,46}$ This is a classic challenge for health systems research in Africa. ${ }^{47}$ To face this challenge, we decided not to include people living in indigence in the CM so as not to make them uncom- fortable in a discussion process where the stakes of power and stigmatization would have been too high. Instead, we took their points of view into account by inviting street level workers who knew their issues in order to bring their voices to this $\mathrm{CM}^{3,48}$ In addition, the follow-up action research made it possible to refine the actions from the indigent people's point of view through numerous focus groups and individual interviews conducted in the capital's neighbourhoods and rural villages concerned. It was essential that both local and national experts and people living in indigence formulated the action to be implemented. This decision was an ethical principle and a desire to effectively formulate the envisaged action.

Regarding the actions proposed by the experts during this concept mapping, beyond their relevance and priority evaluated by the experts, it must be recognized that they correspond to the needs for action for effective care of the indigent in Mali. Their contextual and social relevance is interesting and confirms the adaptation of this group consen- 
sus method to the production of useful reflections. Most of these actions seem to be well adapted to other West African countries. ${ }^{9,49,50}$ This is particularly true when one speaks of four needs:

- Define criteria of indigence and a selection process (community-based) that the social and health administrations of the region have been struggling with;

- An effective reimbursement mechanism for health facilities that must provide free care to the indigent in a context where part of their funding depends on patient payment;

- An efficient administrative system that is coordinated and adapted to register the needy and monitor their situation and that of the health facilities;

- A national and local financing that meets the needs of the poorest.

Finally, based on the whole process from this CM, the analysis of local contexts, and the consideration of the perspectives of the indigent, the content of the action formulated was as follows:

1. To improve communication around RAMED

2. To test the tool (Unified Social Register) before the community identification and instead of the social survey.

3. To organize community identifications

4. To experiment with a fully computerized registration process for indigents.

5. To experiment with individualized monitoring of the indigent by communal social workers.

\section{CONCLUSIONS}

This article has shown that a group consensus technique, such as the CM, is an effective and relevant tool for defining an action. It can be used to define an action and mobilize knowledge linked to the international evidence, the national context, and the local needs of the people concerned. While this study shows that the method is relevant, it is also a means of providing future avenues for action in improving the indigent care in West Africa. Completion of this task will only make sense if these actions are put in place and if they become effective in making the slogan "leaving no one behind" a reality.

\section{ACKNOWLEDGMENTS}

We would like to thank all the steering committee members for their support and participation in this research. Thanks also to Christophe V. W. Seppey for his help in the statistical analysis and the creation of the figures and tables. Finally, thanks to Mahamadou Diabaté for his help around the coordination of this research; and to Heather Hickey for the review. This action research received ethical authorisation from the Institut National de Recherche en Santé Publique in Bamako, Mali (N17/2016/CE-INRSP).

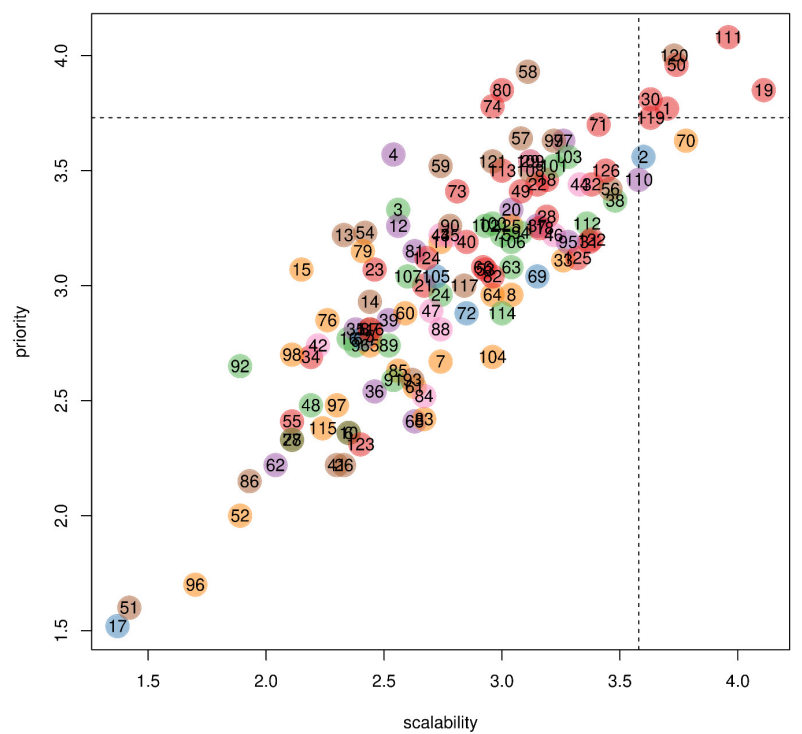

Figure 7. Statements' correlation (priority/ scalability).

\section{FUNDING}

This work has been supported by several donors including the International Development Research Centre. The research was carried out as part of a larger program on "Results-based financing for equitable access to maternal and child health care in Mali and Burkina Faso”. It is part of the 7-year Innovating for Maternal and Child Health in Africa. This research program was implemented by a team of NGOs based in both countries, and researchers from the University of Montreal. In Mali, this team was composed of researchers and research assistants from the NGO MISELI led by Laurence Touré, who is the Principal Researcher of the program.

\section{AUTHORSHIP CONTRIBUTIONS}

MS: Data analysis, paper redaction

LT: Conception and design of the research, data collection

VR: Conception and design of the research, data collection, paper redaction

\section{COMPETING INTERESTS}

"The authors completed the Unified Competing Interest form at www.icmje.org/coi_disclosure.pdf (available upon request from the corresponding author), and declare no conflicts of interest."

\section{CORRESPONDENCE TO:}

Mathieu Seppey

M.P.H., M.Sc., PhD (candidate)

Address: 5051 Berri Street (309), Montreal (Qc), Canada, H2J 2S1 
Submitted: December 22, 2020 GMT, Accepted: March 06, 2021 


\section{REFERENCES}

1. World Health Organization. The World Health Report. Health Systems Financing: The Path to Universal Coverage. 2018;978(92):4.

2. Ridde V. From institutionalization of user fees to their abolition in West Africa: a story of pilot projects and public policies. BMC Health Services Research. 2015;15(S3):S6

3. Ridde V, Sombie I. Street-level workers' criteria for identifying indigents to be exempted from user fees in Burkina Faso. 2012;17(6):782-791. doi:10.1111/j.13 65-3156.2012.02991.x

4. Abbou Y, Brahamia B. Le système de santé algérien entre gratuité des soins et maîtrise des dépenses de santé. J Insaniyat/إنسانياتRevue. 2017;(75-76):149-171.

5. Chen D. Assistance Technique de La Banque Mondiale Sur Le Financement de La Sante En Tunisie: Etude Sur l'assistance Medicale Gratuite. The World Bank; 2016.

6. Ferrié JN, Omary Z, Serhan O. Le Régime d'assistance médicale (RAMed) au Maroc: les mécomptes du volontarisme et de l'opportunisme. 2018;(1):125-143. doi:10.3917/rfas.181.0125

7. Touré L, Ridde V. The emergence of the national medical assistance scheme for the poorest in Mali. Research Square. Published online October 30, 2020. $\underline{\mathrm{d}}$ oi:10.21203/rs.3.rs-22648/v1

8. Balique H, Ouattara O, Ag Iknane A. Dix ans d'expérience des centres de santé communautaire au Mali. 2001;13(1):35-48. doi:10.3917/spub.011.0035

9. Deville C, Escot F, Ridde V, Touré L. Les processus d'identification des plus pauvres à l'épreuve du terrain: une comparaison Bénin-Mali-Sénégal. Published online 2018.

10. Ouattara O, Ndiaye P, Coordination MASMUT zone UEMOA. Potentiel Des Mutuelles de Santé La Mise En Euvre de La Couverture Maladie Universelle Au Mali et Au Sénégal.; 2017.

11. Reason P, Bradbury H. Handbook of Action Research: Participative Inquiry and Practice. Sage; 2001.

12. Aka BRS, Ridde V, Queuille L. L'analyse d'une recherche-action: combinaison d'approches dans le domaine de la santé au Burkina Faso. In: Valéry R, Christian D, eds. Évaluation Des Interventions de Santé Mondiale: Méthodes Avancées. Éditions science et bien commun/IRD Éditions; 2019:125-153.
13. Ridde V, Bonnet E, Kadio K, Louart S, DeAllegri M. La démographie au secours de la couverture santé universelle: exemples en Afrique de l'Ouest. Alternatives Humanitaires. 2019;12(novembre 2019):33-48.

14. Louart S, Bonnet E, Ridde V. Is patient navigation a solution to the problem of "leaving no one behind"? A scoping review of evidence from low-income countries. Health Policy and Planning. Published online 2020. doi:10.1093/heapol/czaa093

15. Ki Zerbo J. L'homme au coeur du développement. In: Modolo MA, Mamon J, eds. IUHPE; 2001:82-93.

16. Trochim WM, Milstein B, Wood BI, Jackson S, Pressler V. Setting objectives for community and systems change: an application of concept mapping for planning a statewide health improvement initiative. Health Promot Pract. 2004;5(1):8-19; discussion 10. doi:10.1177/1524839903258020

17. Risisky D, Hogan VK, Kane M, Burt B, Dove C, Payton M. Concept mapping as a tool to engage a community in health disparity identification. Ethnicity and Disease. 2008;18(1):77.

18. Trochim WMK. An introduction to concept mapping. Eval Prog Planning. 1989;12:1-16.

19. Green J, Thorogood N. Qualitative Methods for Health Research. Sage; 2018.

20. Burke JG, O’Campo P, Peak GL, Gielen AC, McDonnell KA, Trochim WM. An introduction to concept mapping as a participatory public health research method. Qualitative health research. 2005;15(10):1392-1410.

21. Philibert A, Ravit M, Diarra D, Touré L, Ridde V. Évaluation des enquêtes sociales: profil et diagnostic des personnes sélectionnées.

22. Philibert A, Ravit M, Diarra D, Touré L, Ridde V. $\mathrm{Au}$ Mali, la collecte de données des enquêtes sociales réalisées dans le cadre des immatriculations au Régime d'assistance médicale (RAMED) reste à parfaire.

23. Touré L, Ridde V. Au Mali, la mise en œuvre du Régime d'Assistance Médicale (RAMED) est confrontée à des difficultés largement imputables à son montage institutionnel et technique initial. 
24. Touré L, Ridde V. Malgré la volonté affichée du gouvernement malien de prendre en compte les plus pauvres, le montage institutionnel et technique du RAMED a été fait sans la capitalisation de l'expérience acquise.

25. Touré L, Ridde V, Escot F, Diabate S, Karembe Y, Tangara $\mathrm{S}$. Les opérations de ciblage massif et communautaire des indigents, pilotées par l'ANAM, sont sources d'exclusion.

26. Palinkas LA, Horwitz SM, Green CA, Wisdom JP, Duan N, Hoagwood K. Purposeful Sampling for Qualitative Data Collection and Analysis in Mixed Method Implementation Research. Adm Policy Ment Health. 2015;42(5):533-544. doi:10.1007/s10488-01 3-0528-y

27. Péladeau N, Dagenais C, Ridde V. Concept mapping internal validity: A case of misconceived mapping? Evaluation and program planning. 2017;62:56-63.

28. Rosas SR, Kane M. Quality and rigor of the concept mapping methodology: a pooled study analysis. Eval Program Plann. 2012;35(2):236-245. do i:10.1016/j.evalprogplan.2011.10.003

29. Sokal RR. A statistical method for evaluating systematic relationship. University of Kansas science bulletin. 1958;28:1409-1438.

30. Rokach L, Maimon O. Clustering methods. In: Data Mining and Knowledge Discovery Handbook. Springer; 2005:321-352.

31. Hsieh HF, Shannon SE. Three approaches to qualitative content analysis. Qualitative health research. 2005;15(9):1277-1288.

32. Barbour RS. Checklists for improving rigour in qualitative research: a case of the tail wagging the dog? BMJ. 2001;322(7294):1115-1117.

33. Bisung E, Dickin S. Concept mapping: Engaging stakeholders to identify factors that contribute to empowerment in the water and sanitation sector in West Africa. SSM - Population Health. 2019;9:100490. doi:10.1016/i.ssmph.2019.100490

34. Ridde V, Yaogo M, Kafando Y, et al. Challenges of scaling up and of knowledge transfer in an action research project in Burkina Faso to exempt the worstoff from health care user fees. BMC International Health and Human Rights. 2011;11(2):S9. doi:10.1186/ 1472-698X-11-S2-S9
35. Aarons GA, Sommerfeld DH, Chi BH, et al. Concept Mapping of PMTCT Implementation Challenges and Solutions Across 6 sub-Saharan African Countries in the NIH-PEPFAR PMTCT Implementation Science Alliance. JAIDS Journal of Acquired Immune Deficiency Syndromes. 2016;72.

36. Iwelunmor J, Blackstone S, Gyamfi J, et al. A Concept Mapping Study of Physicians' Perceptions of Factors Influencing Management and Control of Hypertension in Sub-Saharan Africa. Pontremoli R, ed. International Journal of Hypertension. 2015;2015:412804. doi:10.1155/2015/412804

37. Israel BA, Schulz AJ, Parker EA, Becker AB. Review of community-based research: assessing partnership approaches to improve public health. Annu Rev Public Health. 1998;19:173-202. doi:10.1146/annurev.publhe alth.19.1.173

38. Jagosh J, Bush PL, Salsberg J, et al. A realist evaluation of community-based participatory research: partnership synergy, trust building and related ripple effects. BMC Public Health. 2015;15:725. doi:10.1186/s12889-015-1949-1

39. Ouédraogo S, Benmarhnia T, Bonnet E, et al. Evaluation of effectiveness of a community-based intervention for control of dengue virus vector, Ouagadougou, Burkina Faso. 2018;24(10):1859.

40. Jaffrè Y. Les objectifs, les séminaires et les recommandations permettent d'améliorer la santé des populations. In: Ridde V, Ouattara F, eds. Des Idées Reçues En Santé Mondiale. Les Presses de l’Université de Montréal; 2015:139-145.

41. Stierle F, Kaddar M, Tchicaya A, Schmidt - Ehry B. Indigence and access to health care in sub - Saharan Africa. TI journal of health planning, management. 1999;14(2):81-105.

42. World Health Organization. Innov8 Approach for Reviewing National Health Programmes to Leave No One behind: Technical Handbook. World Health Organization; 2016.

43. Gilson L, Kalyalya D, Kuchler F, Lake S, Oranga H, Ouendo M \%J H policy. Strategies for promoting equity: experience with community financing in three African countries. 2001;58(1):37-67.

44. Civil Society Engagement Mechanism (CSEM). "Leaving no one behind" Delivering on the promise of health for all: Reflections of the Civil Society Engagement Mechanismfor UHC2030 on the Primary Health Care on the Road toUniversal Health Coverage 2019 Monitoring Report. Published online 2019. 
45. Hunt MR, Gogognon P, Ridde V. Ethical considerations related to participation and partnership: an investigation of stakeholders' perceptions of an action-research project on user fee removal for the poorest in Burkina Faso. BMC Medical Ethics. 2014;15(1):13. doi:10.1186/1472-6939-15-13

46. Yaogo M, Ridde V, Kafando Y, Kadio K. Enjeux disciplinaires, éthiques et politiques d'une rechercheaction sur l'accès aux soins de santé des indigents au Burkina Faso. In: Mondain N, Bologo AE, eds. $L a$ Recherche En Contexte de Vulnérabilité. Engagement Du Chercheur et Enjeux Éthiques. Harmattan; 2012:65-85.

47. Pratt B, Paul A, Hyder AA, Ali J. Ethics of health policy and systems research: a scoping review of the literature. Health Policy Plan. 2017;32(6):890-910. do i:10.1093/heapol/czx003
48. Ridde V, Leppert G, Hien H, Robyn PJ, De Allegri M. Street-level workers' inadequate knowledge and application of exemption policies in Burkina Faso jeopardize the achievement of universal health coverage: evidence from a cross-sectional survey. Int $J$ Equity Health. 2018;17(1):5-5. doi:10.1186/s12939-01 7-0717-5

49. Ridde V, Jacob JP. Les Indigents et Les Politiques de Santé En Afrique. Expériences et Enjeux Conceptuels. Academia (Editions); 2013.

50. Ndiaye S. Le fonds d'équité au Sénégal: analyse des mécanismes de la couverture maladie des indigents et de ses perspectives pour la couverture maladie universelle. Afrique et Développement. 2017;42(1):9-31. 


\section{SUPPLEMENTARY MATERIALS}

\section{Online Supplementary Material}

Download: https://www.joghr.org/article/21956-defining-an-action-research-s-content-to-improve-a-policysupporting-indigents-health-in-mali-a-concept-mapping/attachment/56270.docx 